\title{
Avaliação do Estado Trófico e Proveniência do Fósforo nos Pauis da Praia da Vitória, ilha Terceira, Açores
}

\author{
Evaluation of the Trophic State and Provenance of Phosphorus \\ in the Wetlands of Praia da Vitória, Terceira island, Azores
}

\author{
César Pimentel', Francisco Rodrigues', João Madruga1, Rui Elias² \\ ${ }^{1}$ Mestre. Investigador/Colaborador, Instituto de Investigação e Tecnologias Agrárias e do Ambiente dos Açores, Universidade dos Açores, Rua Capitão João d'Ávila - \\ Pico da Urze 9700-042 Angra do Heroísmo, cesarpimentel.83@gmail.com. \\ ${ }^{2}$ Doutor. Professor Auxiliar. Instituto de Investigação e Tecnologias Agrárias e do Ambiente dos Açores, Universidade dos Açores, Rua Capitão João d'Ávila - Pico da \\ Urze9700-042 Angra do Heroísmo, francisco.c.rodrigues@uac.pt, joao.s.madruga@uac.pt. \\ ${ }^{3}$ Doutor. Professor Auxiliar. CE3C Centre for Ecology, Evolution and Environmental Changes / Azorean B. Universidade dos Açores, Rua Capitão João d'Ávila - Pico da \\ Urze 9700-042 Angra do Heroísmo, elias@uac.pt.
}

RESUMO: O Graben das Lajes localiza-se na vertente Nordeste do vulcão dos Cinco Picos, entre a escarpa das falhas das Fontinhas, a Sudoeste, e a de Santiago a Nordeste. Do ponto de vista hidrogeológico esta zona está associada ao troço mais oriental do aquífero de base da ilha Terceira, recarregado, em grande parte, nas zonas centrais da ilha onde a precipitação é mais elevada. Para além do aquífero basal o Graben das Lajes comporta duas massas de água subterrâneas suspensas localizadas a profundidades distintas. Na zona litoral Sudoeste do Graben das Lajes existem três zonas lagunares associadas a descargas das massas de água acima referidas - os pauis da Praia da Vitória, do Belo Jardim e da Pedreira do Cabo da Praia. Estas massas de água superficiais têm particular importância ecológica, dada a sua grande biodiversidade.

Na determinação do estado trófico dos três pauis foram utilizados dados da concentração de fósforo total cedidos pela Camara municipal da Praia da Vitória no âmbito do Projeto LIFE CWR, entidade responsável pela gestão destas zonas húmidas. Utilizando o fósforo como variável dependente, foi aplicado o índice do estado trófico de Lamparelli (2004).

Quando aplicado o índice trófico aos três pauis, verificou-se que, entre 2016 e 2017, todos se encontravam num estado predominantemente eutrófico.

Palavras-chave: Trófico; Fósforo; Proveniência.

ABSTRAT: The Graben das Lajes is located on the Northeast side of the Cinco Picos volcano, between the escarpment of the Fontinhas faults, to the Southwest, and Santiago to the Northeast. From a hydrogeological point of view, this area is associated with the easternmost section of the basic aquifer on Terceira island, which is largely recharged in the central areas of the island where rainfall is highest. In addition to the basal aquifer, Graben das Lajes comprises two suspended groundwater bodies located at different depths. In the south-west coastal area of Graben das Lajes there are three lagoon areas associated with discharges from the aforementioned bodies of water - the sand of Praia da Vitória, Belo Jardim and Pedreira do Cabo da Praia. These surface water bodies are of particular ecological importance, given their great biodiversity.

In determining the trophic status of the three wetlands, data on the total phosphorus concentration provided by the Praia da Vitória County were used under the LIFE CWR Project, the entity responsible for the management of these wetlands. Using phosphorus as a dependent variable, Lamparelli's trophic status index (2004) was applied.

When the trophic index was applied to the three wetlands, it was found that, between 2016 and 2017, all were in a predominantly eutrophic state

Keywords: Trophic; Phosphorus; Provenance. 


\section{INTRODUÇÃO}

Os ambientes insulares distantes das plataformas continentais têm condicionantes biofísicas, nomeadamente os recursos naturais disponíveis, o isolamento e a dispersão geográfica, aliadas às restrições tecnológicas e aos aspetos socioculturais, que determinam o alcance e a manutenção de um desenvolvimento sustentado. Na generalidade, as ilhas tendem a assentar em especializações produtivas, degradando os recursos naturais de que dependem (Beller et al., 1990).

Os Açores são marcados historicamente pelas monoculturas, ditando a utilização abusiva dos recursos naturais, o que contribui significativamente para alterar a sua paisagem. O crescimento acentuado da pecuária para fins industriais, concretamente a produção de leite que emerge após a Segunda Guerra Mundial, dita o alargamento da área de pastagem, destruindo progressivamente a floresta endémica. Este incremento de gado bovino conduziu à aplicação excessiva de fertilizantes, conduzindo pressões insustentáveis sobre os recursos naturais, com especial incidência para as águas interiores superficiais (e.g. Lagoas) (Porteiro et al., 2005).

Recetoras dos subprodutos da atividade económica dominante (Pecuária) as lagoas e as zonas húmidas apresentam-se muito vulneráveis às pressões a que estão sujeitas, surgindo sinais inequívocos de eutrofização (acréscimo de nutrientes e consequente deterioração dos padrões de qualidade da água, devido à proliferação de algas). A degradação dos ecossistemas lacustres é considerada uma das principais disfunções ambientais do arquipélago, cuja atividade é reconhecida pela população, pela comunidade científica e pela administração regional. $O$ estado destes corpos hídricos é inegavelmente favorecido pelas caraterísticas biofísicas dominantes, como: a pequena dimensão da generalidade das massas de água, responsáveis por elevar a sua sensibilidade a qualquer tipo de pressão de origem antrópica; a morfologia instável e o declive acentuado das vertentes das bacias hidrográficas, o que incrementa o regime de escoamento superficial; a presença de materiais erodíveis como cinzas vulcânicas e cascalho, favorecendo o assoreamento dos planos de água; a prevalência do escoamento difuso (rede hidrográfica pouco hierarquizada), o que dificulta o controlo das entradas de nutrientes (Porteiro \& Calado, 2003).

Do enriquecimento das águas por compostos nutritivos, principalmente por fósforo e azoto, resulta o fenómeno denominado de eutrofização.
Este provoca o crescimento acelerado da vegetação aquática (UNESCO/WMO, 1992), a ocorrência de espumas superficiais, e os desenvolvimentos explosivos de algas ou cianobactérias (Santos et al., 2004). O impacto resultante da eutrofização manifesta-se na composição das comunidades biológicas e nos padrões de qualidade da água (Casas, 1988a). Assim, dependendo da degradação do meio aquático, pode-se classificar as massas de água em classes (estado trófico) que variam entre a oligotrofia e a eutrofia (wetzel, 1993).

A eutrofização das lagoas dos Açores é atualmente considerada uma das maiores disfunções ambientais presentes no arquipélago, designadamente nos impactos verificados na economia, paisagem ou/e na conservação dos recursos naturais (U.N.L.,1991). Neste sentido surgiram alguns trabalhos de ordem científica, principalmente na Lagoa das Furnas e Sete Cidades, onde foram realizadas várias campanhas de amostragem e de monitorização às suas águas avaliando a evolução do estado trófico destes corpos hídricos e, por conseguinte, analisando as possíveis causas da degradação destes sistemas lacustres. Deste modo, foram verificadas as cargas de fósforo máximas permissíveis e as cargas de perigo de eutrofização, usando os valores de referência de Vollenweider (in Harper, 1992) e também os Índices do Estado Trófico (como por exemplo: Carlson (1977).

A finalidade da utilização dos índices de estado trófico reside na classificação dos corpos de água em diferentes graus de trofia, visto que avaliam a qualidade de água quanto ao enriquecimento por nutrientes, nomeadamente o fósforo e o azoto, bem como a clorofila.

Neste trabalho foi utilizado o índice do Estado Trófico (IET) de Lamparelli (2004), adaptado para ambientes lênticos, que utiliza o fósforo como variável dependente.

O IET de Lamparelli (2004) foi desenvolvido para climas subtropicais e tropicais, para ambientes lóticos e lênticos. Os ambientes subtropicais caraterizam-se por estarem presentes em áreas de latitudes compreendidas entre $25^{\circ}$ e $45^{\circ}$, com temperaturas anuais nunca superiores a $20^{\circ} \mathrm{C}$ e mínima nunca menor de $0^{\circ} \mathrm{C}$. Os ambientes tropicais localizam-se em áreas de latitudes entre os $23^{\circ}$ e $26^{\circ}$, com temperaturas anuais médias sempre superiores a $18^{\circ} \mathrm{C}$. Este índice foi desenvolvido a partir do índice de Carlson (1977), que se aplica a regiões temperadas, caraterizadas por apresentarem amplitudes de temperaturas médias elevadas, oscilando entre os $-3^{\circ} \mathrm{C}$ no inverno e $18^{\circ} \mathrm{C}$ no verão.

A temperatura é um fator determinante na 
produtividade primária de um corpo de água, pois as temperaturas muito baixas ou mesmo negativas diminuem muito significativamente a atividade fotossintética (wetzel, 1993).

As zonas hídricas de estudo localizam-se no setor Nordeste da ilha Terceira, designadamente na baía da Praia da Vitória, nos Açores, entre as latitudes $36^{\circ}$ e $43^{\circ}$. O clima é classificado como temperado, sendo o verão seco e temperado ( $\mathrm{Csb}$ ), segundo classificação de Köppen (1936), com valores médios de temperatura no verão que variam entre os $24^{\circ} \mathrm{Ce}$ os $26^{\circ} \mathrm{C}$; e de inverno com temperaturas superiores a $12^{\circ} \mathrm{C}$ nas zonas costeiras (IMP, 2011). Tendo por base o fator temperatura, a aplicação do IET de Lamparelli (2004) nas massas de água em estudo considera-se adequado.

\section{ENQUADRAMENTO}

A ilha Terceira é uma das ilhas constituintes do arquipélago dos Açores, localiza-se no Oceano Atlântico, nas coordenadas: $27^{\circ} 10^{\prime}$ de longitude Oeste e $38^{\circ} 40^{\prime}$ latitude Norte. Tem uma área total de $381,96 \mathrm{~km}^{2}$ e uma população com cerca de 55800 habitantes.

Os pauis da Praia da Vitória (PPV), Belo Jardim (PBJ) e Pedreira do Cabo da Praia (PPCP) localizam-se no sector Sudoeste da ilha Terceira, na orla costeira do Graben das Lajes. Correspondem a pequenas massas de água superficiais associadas a descargas difusas do aquífero basal. Dois destes pauis ocorrem em zonas sedimentares constituídas por dunas, o Paul da Praia da Vitória e do Belo Jardim, e o Paul da Pedreira do Cabo da Praia, numa depressão lávica correspondente a uma antiga pedreira. Em conjunto formam a chamada Infraestrutura Verde Húmida Costeira da Praia da Vitória (IVHCPV) (Pimentel, 2019). São ecossistemas com uma biodiversidade muito rica, com uma grande diversidade de avifauna durante as migrações.

O PPV localiza-se a Sudoeste do Graben das Lajes, a menos de $500 \mathrm{~m}$ da linha de costa junto à cidade da Praia da Vitória. Do ponto de vista hidrológico carateriza-se por apresentar uma lagoa costeira de água salobra, proveniente de uma série de nascentes difusas do aquífero basal e pela entrada de água do mar através de condutas.

Localizado no sector Sudoeste do Graben das Lajes, O PBJ situa-se no extremo da Plataforma das Fontinhas e na faixa litoral da Baía da Praia da Vitória. A sua configuração atual resume-se a uma pequena área lagunar recentemente reabilitada, o que corresponde a $5 \%$ da área primitiva. Esta massa de água superficial, situada junto a um sistema dunar e a menos de $50 \mathrm{~m}$ da linha de costa, carateriza-se por apresentar um nível freático com poucas oscilações. É alimentada por nascentes basais difusas, provavelmente associadas a vias preferenciais de circulação impostas pelas falhas das Fontinhas e do Barreiro (Pimentel, 2019).

O PPCP localiza-se no sector Sudoeste do Graben das Lajes. A sua área lagunar está disposta sobre uma antiga pedreira, onde as escoadas lávicas são periodicamente inundadas por água salgada em função das oscilações da maré. É alimentado pela precipitação, por pequenas descargas difusas do aquífero de base e por nascentes de água doce associadas a pequenos aquíferos suspensos que surgem ao longo das arribas circundantes (Pimentel, 2019).

O clima da ilha Terceira é classificado como temperado, sem estação seca, com verão temperado $(\mathrm{Cfb})$, porém regista-se também um clima temperado com verão seco e temperado (Csb), sobretudo na faixa litoral da ilha (IMP, 2011). Segundo os dados medidos na Estação Meteorológica da Base das lajes, os valores médios anuais da temperatura rondam os $17^{\circ} \mathrm{C}$, sendo agosto o mês mais quente, com temperaturas médias de $21^{\circ} \mathrm{C}$ e máximas de $29^{\circ} \mathrm{C}$, e fevereiro o mais frio, com temperaturas médias de $14^{\circ} \mathrm{C}$ e mínimas de $11^{\circ} \mathrm{C}$ (Novo, 2001).

A precipitação é mais abundante nos meses de novembro, dezembro e janeiro, registando-se em média, durante estes meses, quantidades superiores a $500 \mathrm{~mm}$. Entre os meses de junho e agosto registase uma média de 21,6 mm (IMP, 2011).

Em termos de geologia, a ilha terceira é constituída por três grandes aparelhos vulcânicos distintos: o vulcão dos Cinco Picos, localizado no setor oriental da ilha, o Guilherme Moniz - Pico Alto, disposto no terço central, e o de Santa Bárbara, formando o setor mais ocidental da ilha. De acordo com Rodrigues (2002), os dois primeiros inserem-se no rift da Terceira.

O Graben das Lajes é uma depressão tectónica localizada na vertente Nordeste do vulcão dos Cinco Picos, orientada no sentido Noroeste-Sudeste e limitada pela escarpa de Santiago a Nordeste, pela falha das Fontinhas a SW e pelo mar nos sectores Norte e Sul. De acordo com Rodrigues (1993 e 2002), estas duas falhas, em conjunto com outras que conformam o fundo dessa zona deprimida, onde desempenham um papel crucial na hidrogeologia de toda esta região. O seu estrato geológico é de natureza traquibasáltica, que lhe confere permeabilidades elevadas, com boas taxas de infiltração (Leitão, 2010). Como já foi mencionado anteriormente, devido à grande permeabilidade dos terrenos, a densidade de drenagem é baixa e a rede de cursos de água é pouco estruturada (Rodrigues, 1993). 
No que confere à hidrologia subterrânea, o Graben das Lajes comporta dez aquíferos suspensos dispostos em degrau, formando várias massas de água subterrâneas contiguas (Pimentel, 2019). Comporta ainda um aquífero basal único que abrange a totalidade da ilha Terceira (Paradela, 1980, Rodrigues, 1993 e Rodrigues, 2002), o qual é um dos responsáveis pela existência dos três pauis, através das descargas de nascentes difusas em zonas topograficamente deprimidas (Rodrigues, 2002).

Apesar de geograficamente muito próximos, o uso do solo é um pouco diferenciado em cada um dos três pauis. O PPV localiza-se junto à cidade da Praia da Vitória, está sujeito a pressões de cariz urbano, tais como a descarga de águas pluviais da rede separativa da cidade e também por alguns campos agrícolas a montante. O PBJ insere-se logo atrás do sistema dunar existente na Praia da Riviera e é circundado por pastagens e por um aglomerado pequeno habitacional. Já o PPCP faz fronteira com o mar a Noroeste a Norte por um parque industrial e a NE e Este por pastagens. Deste modo, os pauis encontram-se sujeitos a pressões antrópicas diversas, ou seja pela agricultura, aglomerados urbanos e industriais (Plano de Gestão da Região Hidrográfica dos Açores (PGRH, 2016 - 2021)). Segundo o Plano de Gestão da Região Hidrográfica dos Açores (2016 - 2021), a zona de estudo é considerada como uma das zonas com grandes quantidades de fósforo nas águas subterrâneas (118 Mg/ano) provenientes da formação mais superficial (Ignimbritos das Lajes). A média das bacias hidrográficas da ilha Terceira ronda os 22.7 $\mathrm{Mg} / \mathrm{ano}$, evidenciando cargas difusas relacionadas com a atividade pecuária.

Na figura 1 estão representadas as cargas poluentes estimadas totais anuais de fósforo nas bacias hidrográficas na ilha Terceira. Como se pode observar a zona sudoeste do Graben das Lajes, é uma das que oferece maior risco de poluição associado a este elemento químico.

As cargas de fósforo total nas bacias hidrográficas evidenciam bem o predomínio das cargas difusas, em especial relacionadas com a atividade pecuária, conforme se pode observar na figura 1. Esta é a atividade que mais polui a área de estudo.

No que diz respeito ao risco de poluição tópica doméstica, realça-se a área onde se situa o PPV e o PBJ (Figura 2) e a industrial no PPCP (figura 3).

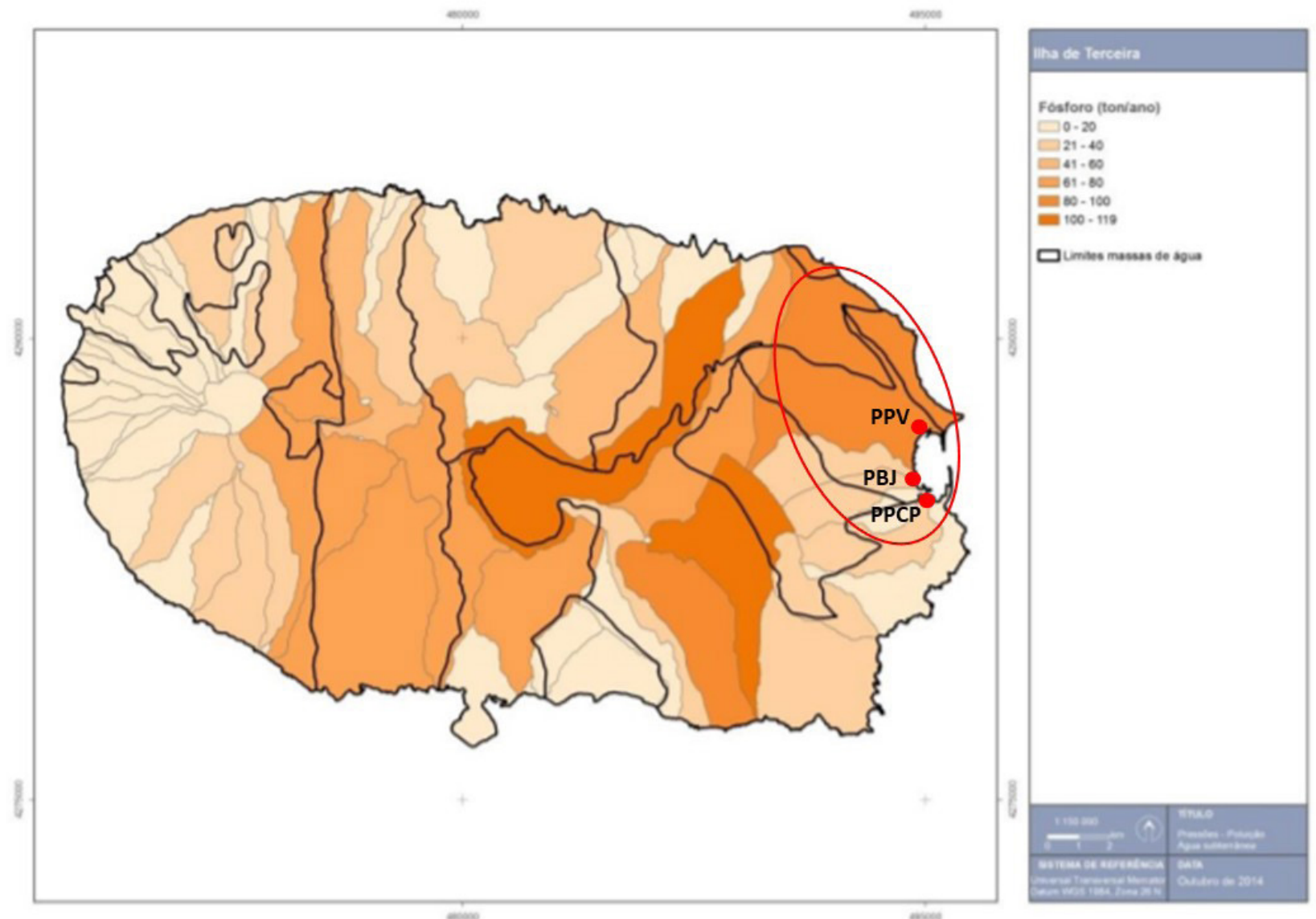

Figura 1. Representação cartográfica de carga poluente de fósforo total na ilha Terceira. Adaptado de PGRH (2016 - 2021$).$ 

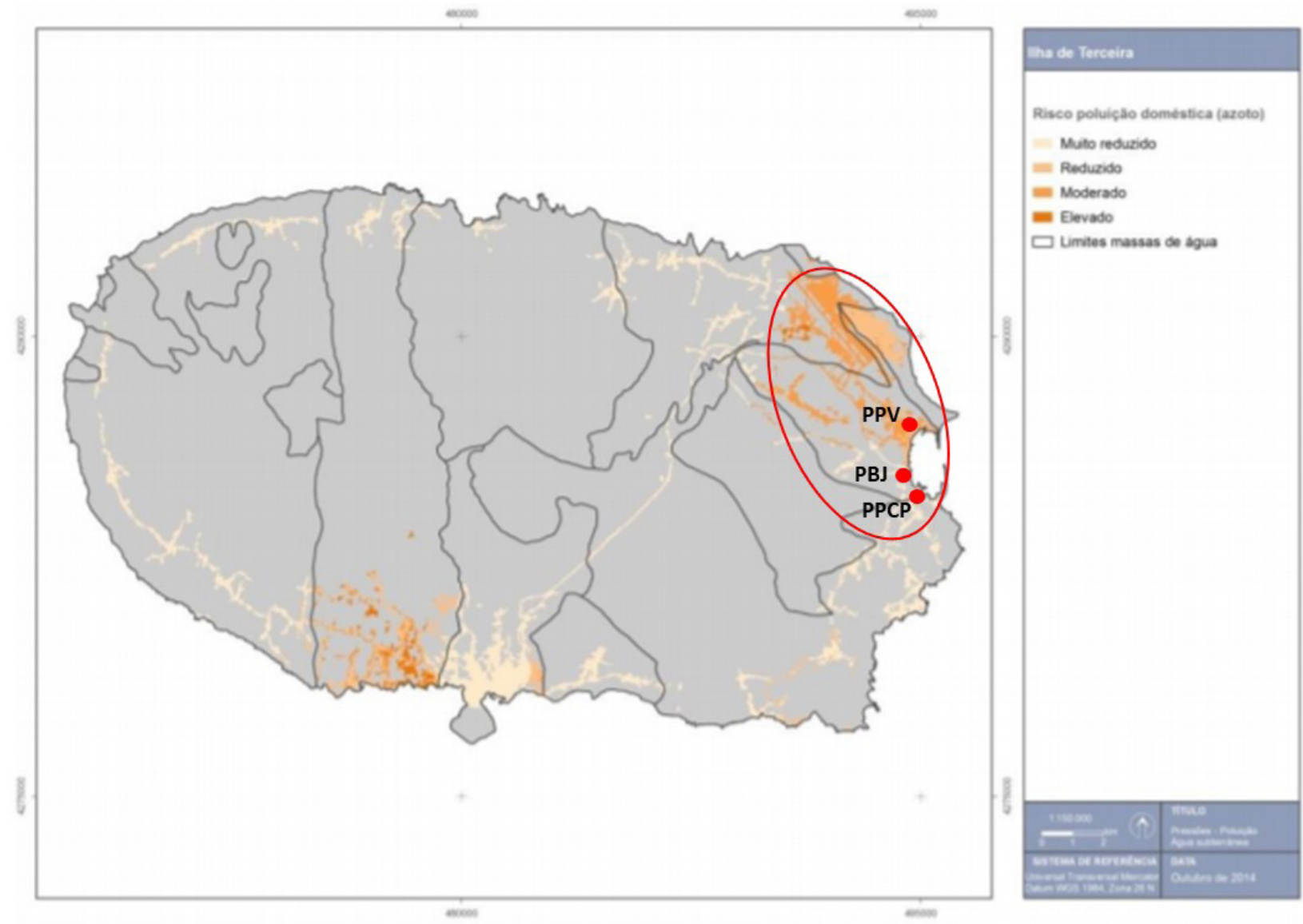

Figura 2. Representação cartográfica de poluição tópica doméstica na ilha Terceira. Adaptado de PGRH (2016 - 2021).
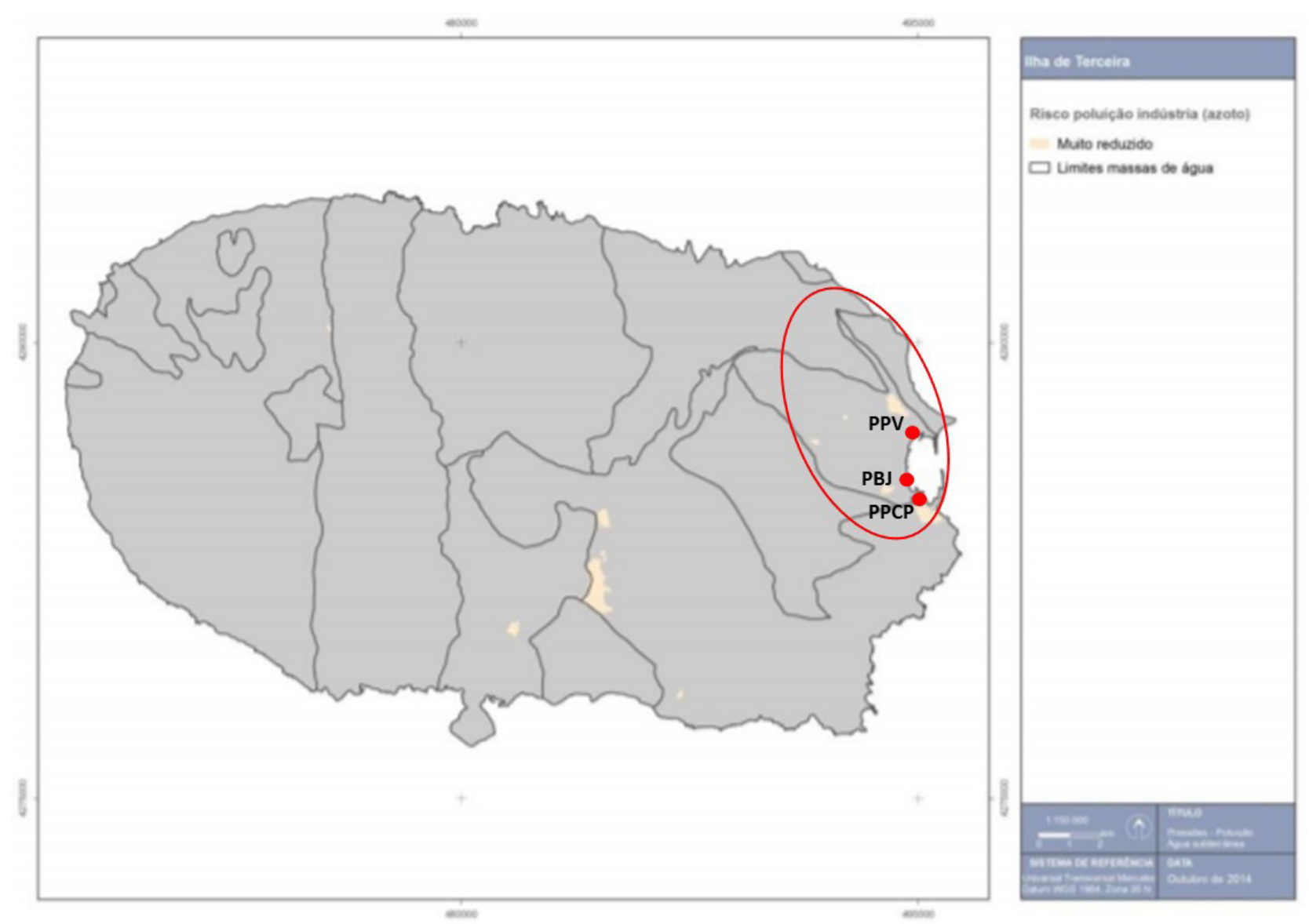

Figura 3. Representação cartográfica de poluição tópica industrial na ilha Terceira. Adaptado de PGRH (2016 - 2021). 


\section{MATERIAL E MÉTODOS}

$\mathrm{Na}$ avaliação do estado trófico foram utilizados dados referentes à concentração de fósforo dos pauis da baía da Praia da Vitória, cedidos pela Camara Municipal da Praia da Vitória no âmbito do Projeto LIFE CWR. As amostras de água foram recolhidas mensalmente pela entidade durante os anos de 2016 e de 2017, e determinadas analiticamente nos laboratórios do INOVA.

Para a avaliação do índice do estado trófico (IET) em ambientes lênticos foi utilizado o Índice de Lamparelli (2004), conforme o especificado na equação 1.

$\operatorname{IET}(P T)=10 *\left(6-\frac{(1,77-0.42 *(\ln P T)}{\ln 2}\right.$

Onde:

IET- Índice de estado trófico em relação à variável fósforo total para ambientes lênticos;

PT- Concentração de fósforo total na superfície ( $\mu \mathrm{g} \mathrm{L})$;

Ln - Logaritmo natural.

$\mathrm{Na}$ interpretação dos resultados utilizou-se a classificação proposta por este autor, utilizando-se as ponderações definidas na Tabela 1.

Tabela 1. Valores limite das concentrações de fósforo total para os diferentes níveis tróficos, segundo a classificação proposto por Lamparelli (2004), (Adaptado de Lamparelli (2004)).

\begin{tabular}{|c|c|}
\hline Estado trófico & Ponderação \\
\hline Ultraoligotrófico & $\mathrm{IET} \leq 47$ \\
\hline Oligotrófico & $47<\mathrm{IET} \leq 52$ \\
\hline Mesotrófico & $52<\mathrm{IET} \leq 59$ \\
\hline Eutrófico & $59<\mathrm{IET} \leq 63$ \\
\hline Supereutrófico & $63<\mathrm{IET} \leq 67$ \\
\hline Hipereutrófico & $\mathrm{IET}>67$ \\
\hline
\end{tabular}

\section{RESULTADOS E DISCUSSÃO}

\subsection{Níveis de fósforo presentes nas zonas húmidas em estudo}

Na Figura 1 expressam-se os teores de fósforo mensais no PPV, PBJ e PPCP entre 2016 e 2017. Como se pode verificar no ano de 2016, o fósforo total no PPV variou entre $49 \mu \mathrm{g} / \mathrm{L}$, no mês de julho, e os $288 \mu \mathrm{g} / \mathrm{L}$ em março, enquanto que em 2017, o valor variou entre $26 \mu \mathrm{g} / \mathrm{L}$ (janeiro) e $333 \mu \mathrm{g} / \mathrm{L}$ (março) (Tabela 2). Este facto demonstra que os níveis deste elemento variam de forma muito significativa, ao longo do ano.
No PBJ apenas estão disponíveis dados referentes ao ano de 2017, após a sua reabilitação e tendo em vista a reconstrução do ecossistema primitivo. Como se pode observar, os valores de fósforo total são elevados, oscilando entre $314 \mu \mathrm{g} / \mathrm{L}$, em maio, e $554 \mu \mathrm{g} / \mathrm{L}$, em abril. A elevada concentração neste paul pode estar relacionada com a atividade agropecuária a montante, onde se aplicam chorumes no mês de março antes das lavouras. Como as pastagens nesta zona se situam a uma cota inferior a $10 \mathrm{~m}$, podem observar-se fenómenos de lixiviação para o aquífero basal, o qual, como já anteriormente referido, é o único responsável pela existência deste corpo hídrico (Tabela 2).

Relativamente ao PPCP, verifica-se no ano de 2016 um valor mínimo de $38 \mu \mathrm{g} / \mathrm{L}$ (novembro) e de 149 $\mu \mathrm{g} / \mathrm{L}$ (agosto). Em 2017, este elemento variou entre $18 \mu \mathrm{g} / \mathrm{L}$ (abril) e $169 \mu \mathrm{g} / \mathrm{L}$ (fevereiro). Dos três pauis monitorizados, este é o que apresenta as menores concentrações de fósforo (Tabela 2), facto a que não pode deixar de estar associada a sua localização. Efetivamente, o PPCP, ao situar-se no extremo sul da Baía da Praia, num local onde se extraiu pedra para a construção do Porto Oceânico da Praia da Vitória, não sofre grande interferência da atividade agropecuária, quer ao nível do escoamento superficial de fertilizantes, quer de processos de lixiviação de chorumes, pois os terrenos a montante situam-se a uma cota superior aos 26 metros.

\subsection{Aplicação do Índice de Lamparelli (2004)}

Na tabela 3 mostra-se para os três pauis o Índice do Estado Trófico de Lamparelli (2004) mensal, bem como a classificação trófica mensal nos anos de 2016 e 2017 e os valores médios deste parâmetro. Da sua análise constata-se o seguinte:

a) nos dois anos em análise no PPV registaram-se estados tróficos que oscilaram entre o mesotrófico $(4,34 \%)$ e o hipereutrófico (17,39\%), sendo em termos médios supereutrófica a água em 2016 e eutrófica em 2017.

b) no PBJ (é) a água é hipereutrófica na (grande) maioria dos registos mensais, com exceção do mês de fevereiro, que registou o estado de supereutrofia c) no PPCP existem vários estados tróficos nos dois anos em análise, com valores que oscilaram entre o mesotrófico, $(39,13 \%)$ e o eutrófico $(60,86 \%)$, sendo em termos médios eutrófico.

Em termos médios, quando aplicado o IET de Lamparelli (2004), verifica-se no PPV a ocorrência de dois estados tróficos, o superreutrófico e o eutrófico, sendo este último dominante praticamente nas quatro estações (Tabela 2). No PBJ verifica-se que independentemente da estação do ano, é o estado hipereutrófico é que predomina (Tabela 3). 
Tabela 2. Concentrações de fósforo mensais registadas no PPV, PBJ e PPCP nos anos de 2016 e 2017, expressos em $\mu \mathrm{g} / \mathrm{L}$.

\begin{tabular}{|c|c|c|c|c|c|c|c|c|c|}
\hline Ano & Mês & PPV & PBJ & PPCP & Ano & Mês & PPV & PBJ & PPCP \\
\hline \multirow{12}{*}{2016} & - & - & - & & \multirow{12}{*}{2017} & Jan & 26 & - & 70 \\
\hline & Fev & 277 & - & 51 & & Fev & 110 & 326 & 169 \\
\hline & Mar & 280 & - & 64 & & Mar & 333 & 402 & 92 \\
\hline & Abr & 135 & - & 62 & & Abr & 62 & 554 & 28 \\
\hline & Mai & 68 & - & 104 & & Mai & 80 & 314 & 84 \\
\hline & Jun & 63 & - & 69 & & Jun & 73 & 486 & 58 \\
\hline & Jul & 49 & - & 67 & & Jul & 159 & 499 & 51 \\
\hline & Ago & 59 & - & 149 & & Ago & 200 & 471 & 41 \\
\hline & Set & 150 & - & 63 & & Set & 225 & 570 & 60 \\
\hline & Out & 156 & - & 58 & & Out & 210 & 381 & 53 \\
\hline & Nov & 166 & - & 38 & & Nov & 91 & 283 & 51 \\
\hline & Dez & 188 & - & 41 & & Dez & 62 & 646 & 29 \\
\hline \multicolumn{2}{|c|}{ Média } & 145 & - & 70 & \multicolumn{2}{|c|}{ Média } & 136 & 448 & 66 \\
\hline \multicolumn{2}{|c|}{ Mediana } & 150 & - & 63 & \multicolumn{2}{|c|}{ Mediana } & 101 & 471 & 56 \\
\hline \multicolumn{2}{|c|}{ Máximo } & 280 & - & 149 & \multicolumn{2}{|c|}{ Máximo } & 333 & 646 & 169 \\
\hline \multicolumn{2}{|c|}{ Mínimo } & 49 & - & 38 & \multicolumn{2}{|c|}{ Mínimo } & 26 & 283 & 28 \\
\hline \multicolumn{2}{|c|}{ Quartil 25} & 66 & - & 55 & \multicolumn{2}{|c|}{ Quartil 25} & 70 & 354 & 49 \\
\hline \multicolumn{2}{|c|}{ Quartil 75} & 177 & - & 68 & \multicolumn{2}{|c|}{ Quartil 75} & 203 & 527 & 74 \\
\hline
\end{tabular}

Tabela 3. Aplicação do IET de Lamparelli (2004) por mês e estação no PPV, PBJ e PPCP.

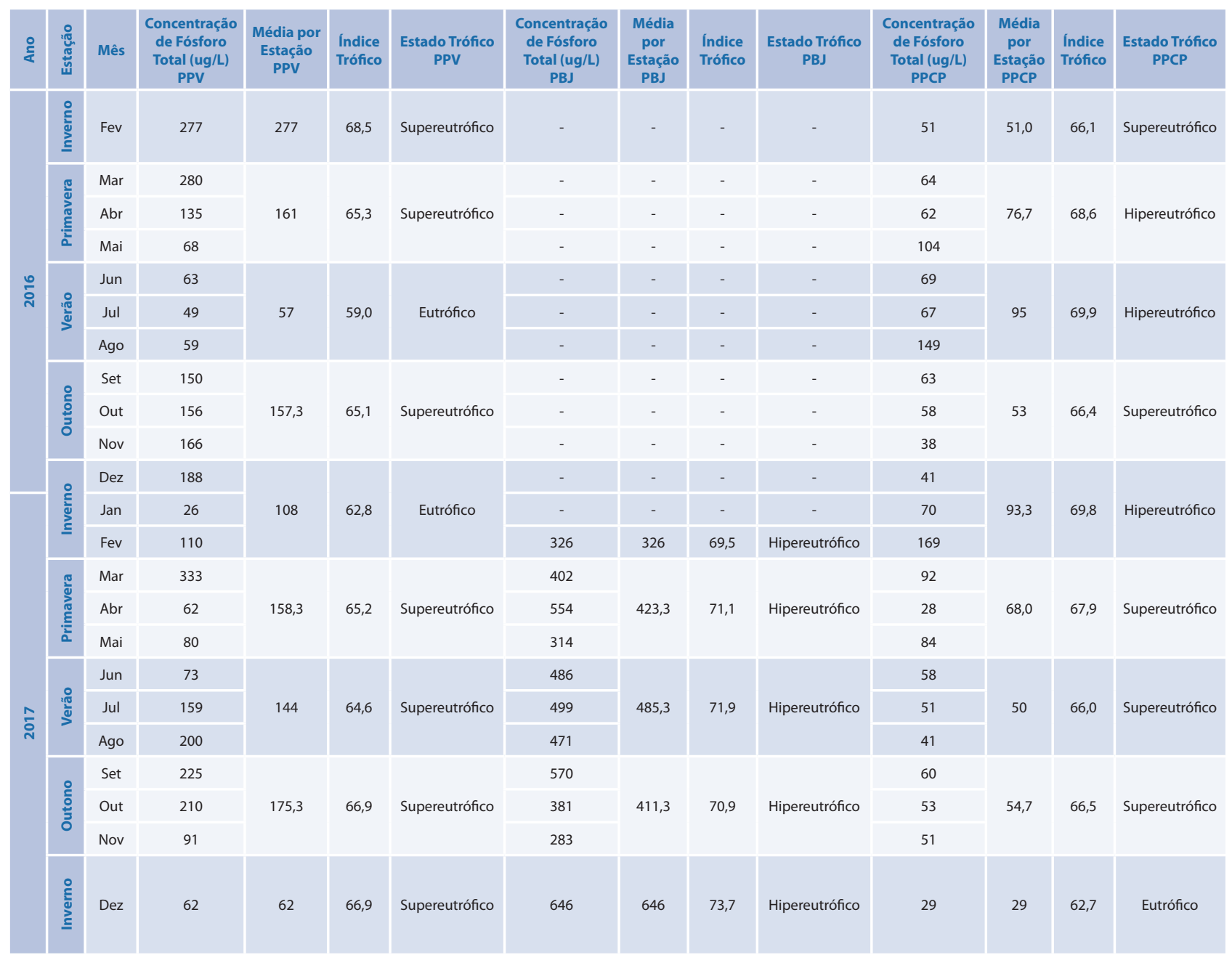


No caso do PPCP constata-se que o IET varia entre eutrófico e hipereutrófico, não havendo um padrão estabelecido, ou seja, na primavera de 2016 obtevese um estado de hipereutrofia e na primavera de 2017, um estado de supereutrofia, o mesmo acontecendo para o resto das estações do ano (Tabela 3).

\subsection{Discussão dos resultados}

Como forma de perceber como se processa a entrada do fósforo nas massas de água estudadas, Pimentel (2019) analisou as correlações entre o fósforo total e a precipitação, temperatura da água, condutividade, $\mathrm{pH}, \mathrm{CBO} 5$ (Carência Bioquímica de Oxigénio aos cinco dias) e CQO (Carência Química de Oxigénio), tendo sido utilizados dados referentes aos anos de 2016 e 2017.

Pimentel (2019) constatou que nenhuma das correlações foi significativa, confirmando que a entrada do nutriente nestes corpos de água depende de outros fatores.

As concentrações de fósforo total no PPV podem ser explicadas pelo transporte direto do nutriente através das condutas pluviais. Estas recebem o escoamento superficial de uma grande parte da cidade da Praia da Vitória, desaguando diretamente neste corpo hídrico, o qual transporta todo o tipo de substâncias químicas, admitindo-se a entrada de detergentes e de outros compostos que integram fósforo. Esta suposição assenta no facto de existirem ligações clandestinas de águas residuais para as condutas de águas pluviais (Pimentel, 2019).

Uma vez que o nível piezométrico do aquífero de base nas imediações do local é muito baixo, na ordem de 1 m (Leitão, 2010 e Pimentel, 2019), a existência de explorações agrícolas e fossas sépticas na vizinhança, pode contribuir para o transporte direto do fósforo para esta massa hídrica via subterrânea, embora de caráter local.

No caso do PBJ, dada a sua orografia relativamente plana do terreno onde está implantado, e a elevada permeabilidade dos terrenos dispostos a montante (dunas), o escoamento superficial até esta massa de água é muito limitado. A sua alimentação fazse sobretudo através de descargas do aquífero de base (Pimentel, 2019).

Em termos comparativos, os níveis de fósforo do PBJ são os mais elevados das três massas de água estudadas. Este facto poderá estar associado à grande atividade agrícola que se faz sentir nas imediações deste corpo hídrico e na existência de várias fossas sépticas muito próximas.

A entrada de fósforo no sistema aquático do PPCP pode ser explicada pelos seguintes fatores: influência bacteriana; fluxo subterrâneo; conduta de águas residuais; e excrementos de aves migratórias.
Segundo Frevert (1979), a comunidade bacteriana em condições de anaerobiose, as trocas inorgânicas nos sedimentos dão-se na interface água-sedimento e são fortemente influenciadas pelas condições redox. A probabilidade de os dos sedimentos terem um papel importante na migração ativa do fósforo para a água é assim considerável. Hynes \& Greib (1970) verificaram que em sedimentos anóxicos não perturbados, em períodos entre 2 a 3 meses, o fósforo desloca-se sem dificuldade para a coluna de água, a uma profundidade de pelo menos $10 \mathrm{~cm}$, independentemente da lama ser eutrófica calcária, ou de natureza turfosa e ácida. Caso exista agitação ou turbulência na água, como é o caso do PPCP, estes autores afirmam que a taxa de libertação de fósforo aumenta e quase duplica.

O fluxo de água subterrâneo neste paul é feito a partir de descargas difusas no aquífero basal e de três aquíferos suspensos, transportando este elemento químico das explorações agrícolas e das freguesias localizadas no sector sul do Graben das Lajes (Pimentel, 2019).

Existe uma conduta de águas residuais proveniente do parque industrial do Cabo da Praia, que desagua junto ao paul, muito provavelmente será esta a entrada mais importante do fósforo na zona húmida, entrando por via das oscilações diárias da maré.

Outra entrada provável de fósforo é feita pelos excrementos das aves, os quais são muito ricos em fósforo, uma vez que o local é muito frequentado por aves marinhas e limícolas nas suas migrações sazonais.

\section{CONCLUSÃO}

Os Açores são caraterizados pelas suas lagoas costeiras, como a Lagoa da Fajã de Santo Cristo e os três pauis em estudo, e pelas suas muitas interiores, como é o caso da Lagoa das Sete Cidades, Lagoa das Furnas, Lagoa do Caldeirão, entre outras. Estas desempenham funções vitais no funcionamento e manutenção dos sistemas naturais das ilhas (Porteiro, 2000), funcionando como ecossistemas de suporte a comunidades de zonas húmidas ameaçadas de extinção (Constância et al., 1997). O Índice do estado trófico de Lamparelli (2004) pode ser considerado como uma boa ferramenta no conhecimento do grau de trofia em ambientes lênticos, tendo em conta que pode ser aplicado nos Açores, mesmo sendo desenvolvido para regiões de climas subtropicais, já que em termos de gradientes de temperatura são muito semelhantes. Este índice apresenta ainda vantagens em relação a outros índices "tradicionais", dado que pode dar a 
indicação do estado trófico a partir da concentração de um só elemento, como fósforo, a clorofila ou a transparência. Esta particularidade torna-se importante em estudos desta natureza, sobretudo em termos de custos, bastando a análise de um só elemento.

A análise do estado trófico para os três pauis permitiu concluir que: quando aplicado Índice do Estado Trófico de Lamparelli (2004), o PPV é classificado como supereutrófico (2016) e eutrófico (2017), enquanto o PBJ é hipereutrófico (2017) e o PPCP é eutrófico em 2016 e 2017.

Ofósforo presente nos três pauis tem provavelmente origens diferenciadas, admitindo-se que no PPV, este chegará através das condutas de águas pluviais e pela migração deste na água subterrânea; no PBJ, a partir de descargas do aquífero basal; e no PPCP, partindo dos sedimentos por influência de bactérias anaeróbicas, migração através de fluxos subterrâneos e excrementos de aves migratórias. Uma das formas de redução das entradas dos elementos químicos responsáveis por fenómenos de eutrofização nos pauis da Praia da Vitória, passa pela forma como é gerido o uso do solo, designadamente a redução da fertilização intensiva das pastagens que circundam o PBJ e o PPCP, e para o PPV um redireccionamento das condutas de águas pluviais. Por fim deverão ser sempre monitorizadas em termos de qualidade de água, acompanhando o seu estado de saúde ecológico.

\section{AGRADECIMENTOS}

Agradece-se ao Projeto LIFE CWR e à Camara Municipal da Praia da Vitoria, em particular à Enga. Elisabete Nogueira, pelo o apoio prestado e pela cedência dos dados que muito contribuíram para a realização deste trabalho.

\section{BIBLIOGRAFIA}

Beller, W., d'Ayala, P.\&Hein, P. 1990. Observations and recommendations of the interoceanic workshop, Puerto Rico, 1986. In: Beller, W., d'Ayala, P. \& Hein, P. (Ed.) Sustainable development and environmental management of small islands, 5:365-396. Man and the Biosphere Series. UNESCO/Parthenon Publishing Group. Paris.

Carlson, R. E. 1977. A trophic state index for lakes. Limnology and Oceanography, 22 (2):361- 369.

Casas, J. 1988a. Características Generales del Processo de Eutrofizacion. Curso sobre la Eutrofizacion de Embalses. Ministério de Obras Publicas y Urbanismo. Madrid.
Constância, J.; Braga, T.; Nunes, J.; Machado, E.; Silva, L. 1997. Lagoas e Lagoeiros da Ilha de São Miguel. Associação Ecológica Amigos dos Açores. Ponta Delgada.

Frevert, T., 1979. Phosphorus and iron concentrations in the interstitial water and dry substance of sediments of Lake Constance (Obersee). Arch. Hydrobiol./Suppl. 55: 298-323.

Harper, D. 1992. Eutrophication of Freshwaters, Chapman \& Hall, London, 327 pp.

Hynes, H. B. N. \& Greib, B.J. 1970. Movement of phosphate and other ions from and through lake muds. J. Fish. Res. Bd. Canada.

Instituto de Meteorologia de Portugal (IMP), 2011: Atlas Climático dos Arquipélagos das Canárias, da Madeira e dos Açores. Temperatura do ar e Precipitação (1971 - 2000).Versão Digital.

KÖPPEN, W., 1936: Das geographisca System der Klimate. En: Handbuch der Klimatologie, band I, teil C. Edited by Köppen, W. and Geiger. Berlin.

Lamparelli, M.C. 2004. Grau de trofia em corpos d'água do estado de São Paulo: avaliação dos métodos de monitoramento. Tese de Doutoramento em Ecologia Aplicada. Universidade de São Paulo, São Paulo.

Leitão T.E., 2010. Análise e Parecer sobre a Situação Ambiental nas Áreas de Captação dos Furos de Abastecimento do Concelho de Praia da Vitoria - Açores. Relatório final das águas subterrâneas. LNEC - Relatório 424/2010 - NAS.

Novo, M.E. Rodrigues, F.C., Lobo Ferreira, J.P., Azevedo, E.B. 2001 - Desenvolvimento de um Inventário das Águas Subterrâneas dos Açores. Fase 3 - Relatório Final. Relatório LNEC 239/01 - GIAS.

Paradela, P.L., 1980. Hidrogeologia Geral das Ilhas Adjacentes. Comun.Serv.Geol. Portugal.

PGRH - Plano de Gestão da Região Hidrográfica dos Açores 2016-2021. Governo dos Açores.

Pimentel, C. M. M. 2019. Avaliação do Sistema Hidrográfico Sudeste do Graben das Lajes. Projeto de Mestrado em Engenharia e Gestão de Sistemas de Água. Universidade dos Açores.

Porteiro, J. \& Calado, H. \& Pereira, M. \& José, E. \& Ventura, J. \& Paramio, L. (2005). Planeamento Biofísico e Gestão de Ecossistemas Lacustres: as Lagoas dos Açores 1. 